it almost impossible to take any therapeutic risk with cases like this.

A. KoTAK, F. NOORE, K. MUTHIAH,

F. RAFFIQUE \& U. SCHMIDT

Paterson Centre for Mental Health,

20 South Wharf Road, London. W2 1PD

\section{Antidepressants in epilepsy}

Sir: While I welcome advice given in the Bulletin with regard to therapeutics, I am in a quandary over the conclusions reached by Duncan and Taylor in response to their question "Which is the safest antidepressant to use in epilepsy?" (Psychiatric Bulletin. 1995, 19, 355-356). They conclude that (MAOIs aside) the agents of first choice should be an SSRI (apart from fluvoxamine) or trazodone.

The specific problem that their conclusions raise is that of viloxazine, an antidepressant not considered in the article, but recommended as "the antidepressant of choice in treating depression in epileptic patients" by Stuart Montgomery (1990. pp 47-48). That the 'guru of SSRIs' should single out a different class of drug for a special indication would make me feel that the authors should have at least mentioned viloxazine and their reasons for not endorsing Montgomery's view.

I would be interested in their retrospective opinion.

MONTGOMERY, S. A. (1990) Anudety and Depression. Petersfield: Wrightson.

\section{MatTHEW JELLEY}

Hillview Lodge, Royal United Hospital,

Bath BA1 3NG

Sir: Dr Jelley refers to Stuart Montgomery's assertion that "the only antidepressant which does not seem to be associated with increased convulsions is viloxazine and it should therefore be regarded as the antidepressant of choice". Our experience of prescribing patterns in of a number of psychiatric institutions leads us to believe that viloxazine is only very rarely used (possibly because it frequently causes headache and nausea). Thus, we feel few prescribers would have experience of using viloxazine and data on its clinical use are, we believe rather limited. This last point is perhaps exemplified by the fact that the Committee on Safety of Medicines have only recelved 169 reports of adverse effects due to viloxazine in 22 years. Interestingly, the CSM have received five reports of convulsions (CSM; personal communication).

We did consider including viloxazine in our article but eventually did not because of its very limited use and because we could find few data to confirm its relatively low propensity to cause seizures.

Denise Duncan and David TaYLoR Maudsley Hospital, Denmark Hill. London SE5 8AZ

\section{The dilemma of psychiatrists in training}

Sir: Psychiatrists in training are often tormented by divided loyalties. As a junior trainee, the pressure to pass the examinations as early as possible overrides academic commitments and commitments to develop patient care skills. In effect, examinations have become a hindrance to academic pursuits, let alone basic professional commitments of those doctors who choose to become psychiatrists. The College offers a research option instead of the essay paper of the examinations. Considering the stipulations attached to this option, it does not seem that the College expects many candidates to attempt it. Once the membership is obtained, the new member immediately joins the rat race to get into a higher training post but with little guidance. By the time this state is achieved many of those psychiatrists in the higher training grades metamorphose into a 'burnt out' state or one of 'self actualisation'. Another hindrance to further achievements in academic or patient care skills is that once in a higher training grade, one is expected to be an authority on all aspects of psychiatry. This view is supported by the observation that those who excel in academic or clinical work do not necessarily do well in the examinations and vice versa. We would suggest that the examination system should relinquish its current fixations and mature out to incorporate assessment of more useful skills than those required to pass the examinations. It will be better if we initiate this rather than someone else imposing it on us.

\section{P. DE VRIES}

Fulbourn Hospital, Cambridge CB1 5EF

O. THACHIL

Worcester Royal Infirmary, Worcester WR5 1JG, M. J. SORE

West Suffolk Hospital, Bury St. Edmunds

IP33 2QZ

A. JoSEPH

Manchester Royal Infirmary, Manchester M13

9WL

A. Michael

S3, Addenbrooke's Hospital, Cambridge CB2 $2 Q Q$ 